\title{
Diffuse Large B-Cell Lymphoma with Anaplastic Clear Cells: A Rare Variant
}

\author{
Mónica Belinda Romero-Guadarrama ${ }^{1 *}$, Leslie Elizmara Aguilar-Ayala ${ }^{1}$, German Ott $^{2}$, \\ Jorge Pérez-Espinosa ${ }^{1}$ \\ ${ }^{1}$ Unit Pathology, Hospital General de México, OD and Medicine School, Autonomous National University of Mexico, Mexico City, \\ Mexico; ${ }^{2}$ Department of Clinical Pathology, Robert-Bosch-Hospital, Stuttgart, Germany. \\ Email: ${ }^{*}$ monicaromero@att.net.mx
}

Received June $20^{\text {th }}, 2012$; revised July $26^{\text {th }}, 2012$; accepted August $6^{\text {th }}, 2012$

\begin{abstract}
Introduction: Diffuse Large B-Cell Lymphoma (DLBCL) is a heterogeneous group conformed by morphological and clinical varieties of neoplasms; it originates from peripheral B-cells and is distinguished into three groups: germinal center (GC), activated B lymphocyte (ABL), and the third type. The existence of DLBCL with anaplastic morphology and expression of $\mathrm{CD} 30$ without $\mathrm{t}(2,5)$ translocation is rare. The aim of the present article is to describe this morphologic variant in a 54-year-old woman and a 74-year-old man, respectively. Materials and Methods: Patients diagnosed with DLBCL with anaplastic variant were identified from the surgical pathology records. Results: Out of 357 biopsies with this diagnosis, 11 (3\%) corresponded to the anaplastic variant, 2 presented morphological clear cells; they became visible because of an increase in volume in the cervical area of 4 months of evolution, usually associated to diaphoresis and weight loss with clinical fulminating progression. An autopsy study was performed to one patient and it showed infiltration in supraclavicular lymph nodes, thyroid, and lung. The neoplastic cells presented abundant clear cytoplasm and pleomorphic nuclei that expressed CD20, CD30 and CD45. Conclusion: This variation is rare. The clinical presentation and prognosis are controversial; we present the morphological and immunophenotype changes of this variant. The differential diagnosis from other clear cell neoplasms should be made.
\end{abstract}

Keywords: B-Cell Anaplastic Lymphoma with Clear Cells

\section{Introduction}

Anaplastic large-cell lymphoma with immunophenotype $\mathrm{B}$ (ALCL-B) is a morphological variant of the diffuse large B-cell lymphoma (DLBCL), according to the classification established by WHO in 2008 [1]; it was recognized by its expression of the Ki-1 antibody, now CD30. Neoplastic cells that expressed CD30 derived from T-cells and they were denominated Ki-1 Lymphomas. It is now recognized that there is a small number of cases with the B immunophenotype [2].

This type of lymphoma appears in lymph nodes and is identical to its counter part T-cell lymphoma. It had not been identified for a long time [3-5] and it is characterized by the presence of large cells from abundant to scarce cytoplasm and with round, oval and pleomorphic nuclei. Some cells can be gigantic, they express B markers such as CD19 or CD20, among others, and CD30 as the activation marker. They can be morphologically indistinct from carcinomas because of their histological appearance.

\footnotetext{
"Corresponding author.
}

There are few cases published and its frequency remains unknown. However, in the study performed by Weisenburger and colleagues, it represented $3.4 \%$ of total non-Hodgkinlymphomas [6].

Clinical presentation and prognosis are similar to other types of diffuse large B-cell lymphoma. However, in a study performed by the French group GELA, a small number of cases of this type of lymphomas, badly predicted [7] was reported.

The aim of the present article is to present the clinical, morphological, and immunophenotypic characteristics of this variation with cells that present a clear cytoplasm.

\section{Materials and Methods}

\section{Case Selection}

During a period of eight years, we studied 357 DLBCL from the surgical pathology records in the Pathology Unit of the General Hospital of Mexico; 11 (3.0\%) of these cases corresponded to an anaplastic morphology, 2 cases were selected out of these 11 due to the presence of clear cells. In every case, clinical records and histo- 
logical sections were verified.

The histological sections were cut at $4-\mu \mathrm{m}$ thickness and they were stained with hematoxylin-eosin and periodic acid-Schiff stain. Representative sections were chosen in order to perform manually the immunoperoxidase technique. The technique consisted in using avidin-biotin-peroxidase with previous antigenic recuperation, for this reason, citrate buffer was used at $99^{\circ} \mathrm{C}$, for $10 \mathrm{~min}$ utes in a pressure cooker.

Monoclonal antibodies were CD20 (L-26 clone DakoCytomation), CD3 (rabbit monoclonal antibodies; DakoCytomation), CD10 (clone 56C; Novocastra Laboratories), bcl2 (clone 124; DakoCytomation), bcl6 (clonePGB6p; DakoCytomation), MUM 1 protein (cloneMUM1p; DakoCytomation), LMP-1 (clone Zebra/DakoCytomation), CD30/Ki-1 (DakoCytomation), epithelial membrane antigen (DakoCytomation), cytokeratins 10/ 13 (DakoCytomation), Lysozyme (DakoCitomation), CD1a (DakoCytomation and PS100 (DakoCytomation). For their microscopic evaluation, they were developed with diaminobenzidine.

EBER (in situ hybridization for Epstein-Barr virus) technique was performed to determine the presence of Epstein-Barr virus (EBV) in the nuclei of neoplastic cells; for this, tests of labinized peptide nucleicacid of fluorocyanate were used to determine the presence of nuclearencoded RNA. Alkaline phosphatase-conjugated, rabbit antibodies and anti-fluorescein isothiocyanate were added, followed by 4-nitroblue tetrazolium/5-bromo-4-chloro3-indolyl phosphate (NBT/BCIP; Roche Diagnostics, Indianapolis, IN, USA). It was contrasted with Gill's hematoxylin and the final procedure was followed just like in the immunoperoxidase technique, already described. We used a nasal NK/T-cell lymphoma sample as a positive external control.

\section{Results}

\subsection{Description of Cases}

\subsubsection{Case 1}

A 54-year-old woman with progressive increase of cervical lymphadenopathies of $4 \times 3 \mathrm{~cm}$ of 4 months of evolution, presence of diaphoresis, asthenia, adynamia, and $10 \mathrm{~kg}$ weight loss. Biopsy was performed. Clinical follow: The patient was lost due to institutional change for treatment.

\section{Macroscopic findings}

We received an ovoid sample of $3 \times 2 \mathrm{~cm}$, gray-white color and consistency of rubber, the surface of the section was homogeneous. It was fixed in $10 \%$ formaldehyde.

\subsubsection{Case 2}

A 74-year-old man with a progressive increase in volume of the left side of the neck of 4 months of evolution; asthenia and adynamia were added. The physical examination showed the increase in volume of the left side of the neck of $10 \times 15 \mathrm{~cm}$ that affected submandibular and cervicallymph nodes. Laboratory tests revealed LDH of 418 and $611 \mathrm{U} / \mathrm{L}$.

Computed axial tomography, abdominal-thoracic region with no alterations, and bone marrow biopsy was performed. Treatment was established by CHOP. Subsequently, he presented respiratory difficulties, tonic-clonic convulsions, and died. Autopsy was done.

\subsection{Macroscopic Findings}

The sample obtained from the lymph node conglomeration corresponded to several tissue fragments of irregular form and of gray-white color of $2 \times 2 \mathrm{~cm}$. They were fixed in $10 \%$ formaldehyde.

The autopsy study revealed the presence of a left sided lymph node conglomeration of $16 \times 12 \times 14 \mathrm{~cm}$, with a "fish/meat" aspect, gray and white color that infiltrated into de soft tissues of the neck and muscles, cartilage, trachea and larynx wall. A neoplastic infiltration was observed in the lower-left pole of the thyroid and in lungs. The rest of the organs were found irrelevant.

\subsection{Histopathology}

Both samples corresponded to cervical lymph nodes, in which a neoplasm constituted by a capsule of connective tissue with large cells of abundant clear cytoplasm was observed; the large cells were negative in the presence of glycogen with PAS stain. The nuclei of cells were ovoid, irregular, some cells with two nuclei, with lobes and evident nucleoli. We observed small reactive lymphocytes and sclerosis among the neoplastic cells (Figures 1 and 2). Immunohistochemical reactions demonstrated

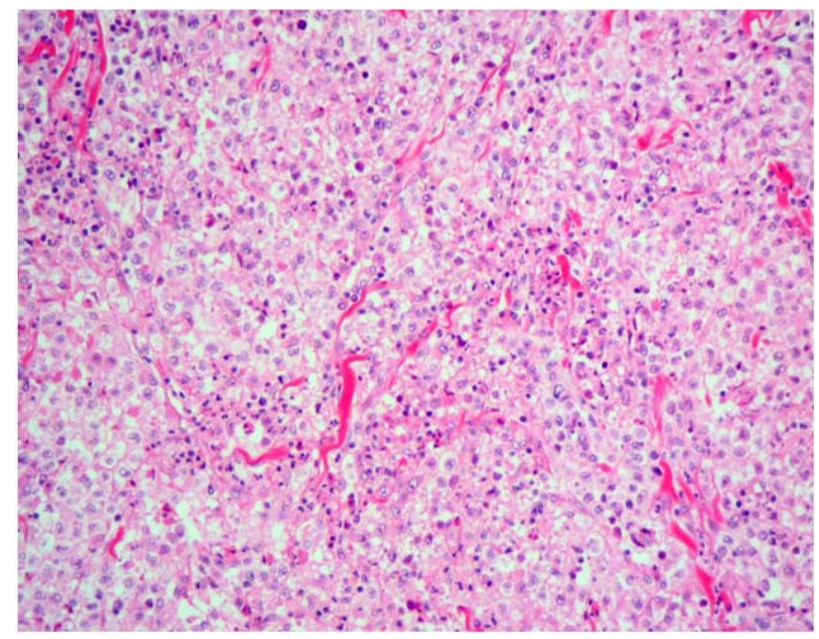

Figure 1. Diffuse proliferation of large cells with clear cytoplasm (H-E 10×). 


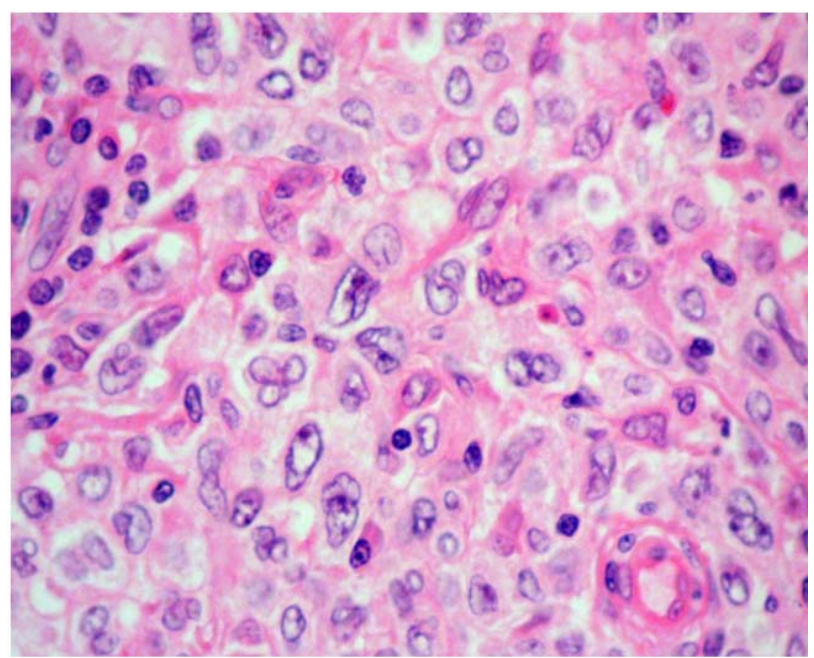

Figure 2. Cells with clear cytoplasm and pleomorphic nuclei (H-E 40×).

CD20, CD45, and CD30 positivity (Figures 3 and 4). Other markers tested, such as: antigen of epithelial membrane, lysozyme, CD 1a, Ps-100, cytokeratins, CD 10, bcl2, bcl6, Mum-1, and EBER, were all negative.

\section{Discussion}

Anaplastic DLBCL is characterized by a cellular proliferation with pleomorphic or anaplastic morphology and by expression of the CD30 marker. In the past, it used to be diagnosed as immunoblastic lymphoma or malignant histiocytosis. Anaplastic DLBCL can also simulate malignant melanoma and undifferentiated carcinoma. The present report describes a rare variant of DLBCL with morphological characteristics of cells showing a clear cytoplasm, localized in cervical lymph nodes. The B-lymphoma that constantly presents cells with clear cytoplasm is originated in the mediastinum, and the initial reports appeared in the early 1980s. It as a tumor different from lymphoblastic T-cell lymphoma, thymiccarcinoma, or sarcomas $[8,9]$.

This B-lymphomais located in the mediastinum, in the anterior superior area; it is frequently associated to sclerosis with dissemination through different places. It is presumed to be originated from thymic B-cells situated around the vessels between the cortex and medulla of the organ [10]; some immunophenotypic characteristics of neoplastic cells indicate that they are originated from terminal B-cell and gene expression profiling showed a unique expression profile [11]. It is infrequent and represents about $2.4 \%$ of all types of lymphoma $[1,12]$. Contrary to the reported cases in the present article; clinically, it is present in young women between 36 and 39 years of age and, as mentioned before, it initially occurs in the anterior mediastinum and disseminates through extranodal areas such as kidney, adrenal gland,

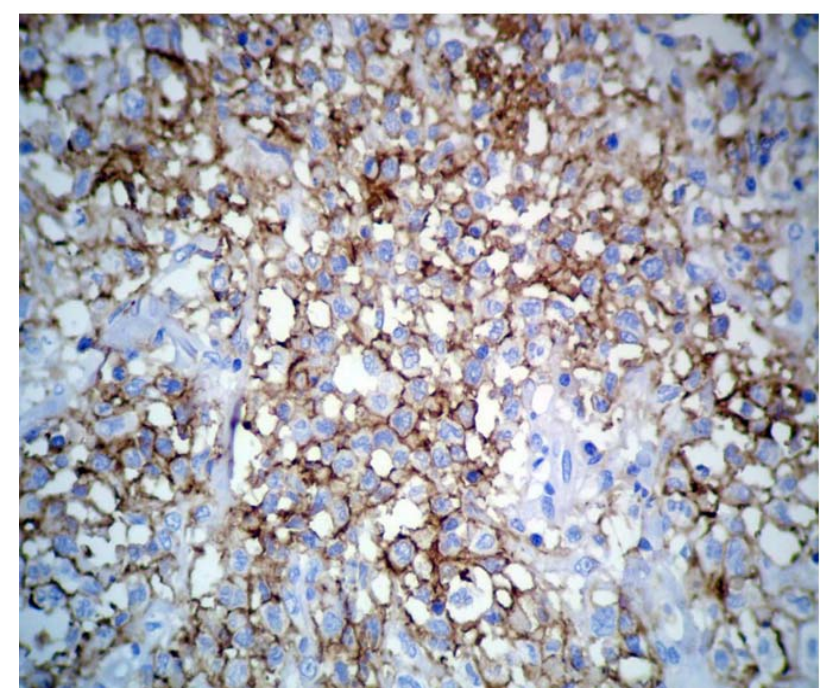

Figure 3. CD20 is positive in the cytoplasmic membrane of the neoplastic cells (Immunoperoxidase 10×).

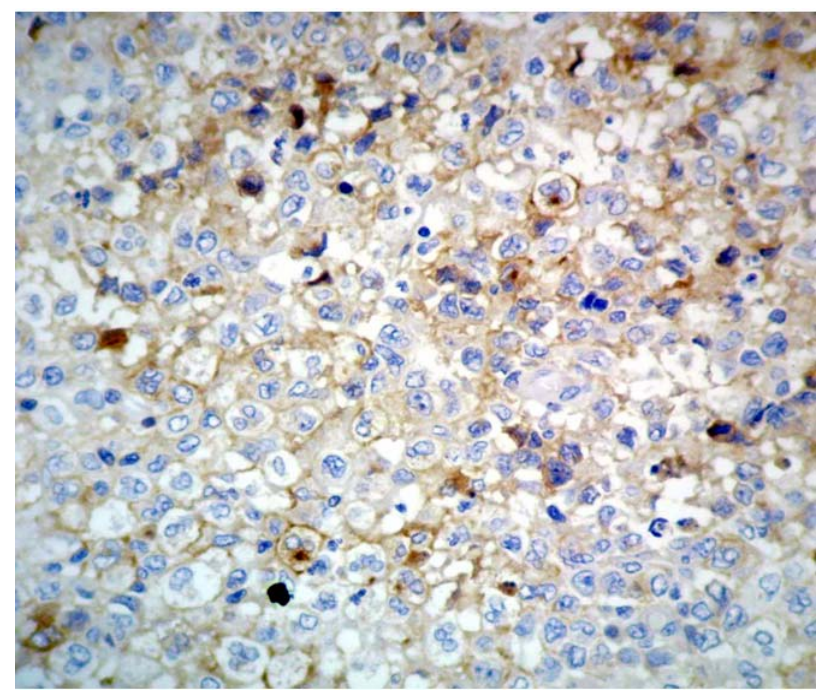

Figure 4. Expression of CD30 in most of the cells is shown (Immunoperoxidase 10 $\times$ ).

liver and central nervous system [13].

In our patients, the initial area for the clinical presentation was the cervical lymph node. The autopsy study revealed local infiltration into cervical soft tissues, thyroid gland, and lung. The bone marrow was not infiltrated.

This DLBCL variant has not been sufficiently studied because it has been reported only in a small percentage of cases (less than 20\%) [14,15].

The cells are morphologically large with abundant cytoplasm, giant cells. The so called decoy cells (hallmark cells) can be observed with an increasing diffuse pattern or sinus condition. Other morphological types described are small and fusiform cells [1]. In this study, we observed large cells of abundant clear cytoplasm and irregular, fissured, lobed nuclei and, occasionally, with 
visible nucleolus. Among neoplastic cells, small lymphocytes and limited collagen fibers were observed. Decoy cells were not visible in any of the two samples. By definition, neoplastic cells display expression of B markers such as CD19, CD20, and CD22 combined with CD30 expression, this last marker is changeable and it can be in the cytoplasmic membrane of the cells or in the cytoplasm. In the cases presented in this report, CD30 expression occurred in both the cytoplasmic membrane and the cytoplasm with paranuclear distribution. Other activation markers that can be considered in this type of lymphoma are CD23, CD21, CD38, CD71, CD25, and CD45 [3,16].

Unfortunately, we did not performa molecular study; however, it has been informed previously about the clonal IgH rearrangement in 3 of 5 cases by Southern blot hybridization [16]. Using other methods, like polymerase chain reaction (PCR), it was possible to notice the $\mathrm{IgH}$ gene rearrangement in $59 \%$ of anaplastic lymphomas with B-immunophenotype [17]. Average mutation observed in this lymphoma is $13 \%$, similar to other cases of DLBCL, follicular lymphoma and Hodgkin's lymphoma. Somatic mutations suggest that this lymphoma comes from B-cells of the germinal center or post-germinal [17]. By immunophenotype, we were not able to reveal expression of markers, the germinal center, or the activated lymphocyte; for this reason, we believe that this variant corresponds to the so-called third type. The presence of the Epstein-Barr virus (EBV) has been analyzed showing variable results, using several techniques. In the cases here presented, it was not possible to observe such an association. In the Japanese study group, an association of EBV with the lymphoma in $35 \%$ of 17 cases studied was found $[18,19]$. In another series of 16 cases, an association frequency of $19 \%$ was observed [20]. This piece of information must be taken carefully, because many types of lymphoma exist that are associated with the presence of this virus.

Differential diagnosis must be performed in regard to B-immunoblastic lymphoma with the presence of clear cells, from T-anaplastic lymphoma, associated or not to the expression of ALK (Anaplastic lymphoma kinase) and from metastatic carcinoma that presents clear cells similar to kidney cells. Immunohistochemistry markers have a relevant role in the differential diagnosis [1].

In conclusion, we presented two rare cases of diffuse large B-cell lymphoma, an anaplastic morphological variant, where most of the cells presented clear cytoplasm in two adults older than 50 years, not associated to Epstein-Barr virus and with fulminant clinical course. We consider important the description of this variant in order to know better its biology and morphological aspect for further studies.

\section{REFERENCES}

[1] H. Stein, R. A. Warnke, W. C. Chan, E. S. Jaffe, J. K. C. Chan, K. C. Gatter and E. Campo, "Diffuse Large B-Cell Lymphoma, Not Otherwise Specified," In: S. H. Swerdlow, E. Campo, N. L. Harris, E. S. Jaffe, S. A. Pileri, H. Stein, J. Thiele, J. W. Vardiman, Eds., WHO Classification of Tumours of Haematopoietic and Lymphoid Tissues, 4th Edition, WHO Press, Lyon, 2008, pp. 233-237.

[2] K. Lennert and A. C. Feller, "Histopathology of NonHodgkin's Lymphomas," Based on the Updated-Kiel Classification, 2nd Edition, Springer-Verlag, Berlin, 1992, p. 152.

[3] T. Kuze, N. Nakamura, Y. Hashimoto, M. Abe and H. Wakasa, "Clinicopathological, Immunological and Genetic Studies of CD30+ Anaplastic Large Cell Lymphoma of B-Cell Type; Association with Epstein-Barr Virus in a Japanese Population," Journal of Pathology, Vol. 180, No. 3, 1996, pp. 236-242. doi:10.1002/(SICI)1096-9896(199611)180:3<236::AID-P ATH653>3.0.CO;2-D

[4] M. Engelhard, G. Brittinger, D. Huhn, H. H. Gerhartz, P. Meusers, W. Siegert, E. Thiel, W. Wilmanns, U. Aydemir, S. Bierwolf, H. Griesser, M. Tiemann and K. Lennert, "Subclassification of Diffuse Large B-Cell Lymphomas According to the Kielclassification: Distinction of Centroblastic and Immunoblastic Lymphomas Is Asignificant Prognostic Risk Factor,” Blood, Vol. 89, No. 7, 1997, pp. 2291-2297.

[5] H. Tilly, P. Gaulard, E. Lepage, C. Dumontet, J. Diebold, I. Plantier, F. Berger, M. Symann, T. Petrella, P. Lederlin and J. Brière, "Primary Anaplastic Large-Cell Lymphoma in Adults: Clinical Presentation, Immunophenotype, and Outcome," Blood, Vol. 90, No. 9, 1997, pp. 3727-3734.

[6] D. D. Weisenburger, J. R. Anderson, J. Diebold, R. D. Gascoyne, K. A. MacLennan, H. K. Müller-Hermelink, B. N. Nathwani, F. Ullrich and J. O. Armitage, "Systemic Anaplasticlarge-Cell Lymphoma: Results from the NonHodgkin's Lymphoma Classification Project," American Journal of Hematology, Vol. 67, No. 3, 2001, pp. 172 178. doi:10.1002/ajh.1102

[7] J. Diebold, J. R. Anderson, J. O. Armitage, J. M. Connors, K. A. Maclennan, H. K. Müller-Hermelink, B. N. Nathwani, F. Ullrich and D. D. Weisenburger, "Diffuse Large B-Cell Lymphoma: A Clinicopathologic Analysis of 444 Cases Classified According to the Updated Kiel Classification," Leukemia \& Lymphoma, Vol. 43, No. 1, 2002, pp. 97-104. doi:10.1080/10428190210173

[8] H. G. Zhuang, G. Z. Liang, W. C. Li, Y. Q. Zhang, R. Z. Guo, S. L. Liu and N. X. He, "Clear Cell Lymphoma: A Clinicopathological Study of Four Cases," Human Pathology, Vol. 19, No. 7, 1988, pp. 760-765. doi:10.1016/S0046-8177(88)80258-2

[9] P. Möller, B. Lämmler, M. Eberlein-Gonska, G. E. Feichter, W. J. Hofmann, H. Schmitteckert and H. F. Otto, "Primary Mediastinal Clear Cell Lymphoma of B-Cell Type," Virchows Archiv A, Pathological Anatomy and Histopathology, Vol. 409, No. 1, 1986, pp. 79-92. doi:10.1007/BF00705408

[10] P. G. Isaacson, A. J. Norton and B. J. Addis, "The Human 
Thymus Contains a Novel Population of B Lymphocytes," Lancet, Vol. 2, No. 8574, 1987, pp. 1488-1491. doi:10.1016/S0140-6736(87)92622-5

[11] P. Möller, G. Moldenhauer, F. Momburg, B. Lämmler, M. Eberlein-Gonska, S. Kiesel and B. Dörken, "Mediastinal Lymphoma of Clear Cell Type Is a Tumor Corresponding Toterminal Steps of B Cell Differentiation," Blood, Vol. 69, No. 4, 1987, pp. 1087-1095.

[12] J. O. Armitage and D. D. Weisenburger, "New Approach to Classifying Non-Hodgkin's Lymphomas: Clinical Features of the Major Histologic Subtypes, Non-Hodgkin's Lymphoma Classification Project," Journal of Clinical Oncology, Vol. 16, No. 8, 1998, pp. 2780-2795.

[13] P. C. Bishop, W. H. Wilson, D. Pearson, J. Janik, E. S. Jaffe and P. C. Elwood, "CNS Involvement in Primary Mediastinal Large B-Cell Lymphoma," Journal of Clinical Oncology, Vol. 17, No. 8, 1999, pp. 2479-2485.

[14] H. Stein, D. Y. Mason, J. Gerdes, N. O’Connor, J. Wainscoat, G. Pallesen, K. Gatter, B. Falini, G. Delsol, H. Lemke, et al., "The Expression of the Hodgkin's Disease Associated Antigen Ki-1 in Reactive and Neoplastic Lymphoid Tissue: Evidence That Reed-Sternberg Cells and Histiocytic Malignancies Are Derived from Activated Lymphoid Cells," Blood, Vol. 66, No. 4, 1985, pp. 848858.

[15] J. K. Chan, C. S. Ng, P. K. Hui, T. W. Leung, E. S. Lo, W. H. Lau and L. J. McGuire, "Anaplastic Large Cell Ki-1 Lymphoma. Delineation of Two Morphological Types," Histopathology, Vol. 15, No. 1, 1989, pp. 11-34.

\section{Abreviations}

DLBCL $=$ Diffuse Large B Cell- Lymphoma

$\mathrm{GC}=$ Germinal Center

ALCL-B = Anaplastic Large-Cell Lymphoma with Immunophenotype B

\section{doi:10.1111/j.1365-2559.1989.tb03038.x}

[16] H. Herbst, G. Tippelmann, I. Anagnostopoulos, J. Gerdes, R. Schwarting, T. Boehm, S. Pileri, D. B. Jones and H. Stein, "Immunoglobulin and T-Cell Receptor Gene Rearrangements in Hodgkin's Disease and Ki-1-Positive Anaplastic Large Cell Lymphoma: Dissociation between Phenotype and Genotype," Leukemia Research, Vol. 13, No. 2, 1989, pp. 103-116. doi:10.1016/0145-2126(89)90134-3

[17] T. Kuze, N. Nakamura, Y. Hashimoto and M. Abe, "Most of CD30+ Anaplastic Large Cell Lymphoma of B Cell Type Show a Somatic Mutation in the IgH V Region Genes," Leukemia, Vol. 12, No. 5, 1998, pp. 753-757.

[18] I. Anagnostopoulos, H. Herbst, G. Niedobitek and H. Stein, "Demonstration of Monoclonal EBV Genomes in Hodgkin's Disease and Ki-1-Positive Anaplastic Large Cell Lymphoma by Combined Southern Blot and in Situ Hybridization," Blood, Vol. 74, No. 2, 1989, pp. 810-816.

[19] H. Herbst, F. Dallenbach, M. Hummel, G. Niedobitek, T. Finn, L. S. Young, M. Rowe, N. Müller-Lantzsch and H. Stein, "Epstein-Barr Virus DNA and Latent Gene Products in Ki-1 (CD30)-Positive Anaplastic Large Cell Lymphomas," Blood, Vol. 78, No. 10, 1991, pp. 2666-2673.

[20] M. Hummel, I. Anagnostopoulos, P. Korbjuhn and H. Stein, “Epstein-Barr Virus in B-Cell Non-Hodgkin's Lymphomas: Unexpected Infection Patterns and Different Infection Incidence in Low- and High-Grade Types," Journal of Pathology, Vol. 175, No. 3, 1995, pp. 263-271.

\author{
WHO $=$ World Health Organization \\ GELA $=$ French Group \\ $E B E R=$ In Situ Hybridization for Epstein-Barr Virus \\ $\mathrm{PCR}=$ Polymerase Chain Reaction
}

